Research Article

\title{
Research on the Mechanism of Cold Chain Logistics Subsidy
}

\author{
Nai-Ru Xu $\mathbb{D}^{1}$ and Zheng-Qun Cai $\mathbb{D}^{2}$ \\ ${ }^{1}$ School of Business, Anhui Xinhua University, Hefei 230088, China \\ ${ }^{2}$ School of Foreign Studies, Anhui Jianzhu University, Hefei 230601, China \\ Correspondence should be addressed to Zheng-Qun Cai; caizhengqun1983@163.com
}

Received 31 October 2019; Accepted 12 March 2020; Published 19 April 2020

Guest Editor: Shaohui Wang

Copyright (c) $2020 \mathrm{Nai}-\mathrm{Ru} \mathrm{Xu}$ and Zheng-Qun Cai. This is an open access article distributed under the Creative Commons Attribution License, which permits unrestricted use, distribution, and reproduction in any medium, provided the original work is properly cited.

\begin{abstract}
Considering the coexistence of cold chain agro-products and ordinary agro-products in the market, the research object is the cold chain logistics subsidy. It is designed that a supply chain system consisting of duopoly upstream agro-products suppliers and a downstream agro-products retailer for research. The mechanism of cold chain logistics subsidy is studied by analyzing the influence of cold chain subsidy on pricing behavior and cold chain decision-making of cold chain agro-products and ordinary agro-products. Based on the decentralized decision-making model without government subsidy, a differential pricing model for cold chain agro-products and ordinary agro-products with government subsidy is established in order to reduce the cost of cold chain agro-products. The optimal pricing strategy of two agro-products suppliers and their downstream retailer can be obtained by solving this problem. The research finds that differential pricing caused by government subsidy can achieve profit Pareto improvement of suppliers, retailer, and supply chain system of cold chain agro-products, but cannot achieve the optimal profit of the whole supply chain. Therefore, in view of the loss of supply chain efficiency caused by decentralized decision-making, the Shapley value method is used to make coordination, and the contract coordination mechanism is designed. Finally, the sensitivity of parameters is analyzed by a numerical example.
\end{abstract}

\section{Introduction}

Cold chain logistics generally refers to a systematic engineering in which the refrigerated and frozen food is always in the specified low-temperature environment in the segments of production, transportation, storage, and sale, as well as consumption, in order to ensure food quality and reduce the loss. With China's economic and social development and the continuous improvement of people's living level, consumers are increasingly demanding high-quality fresh products and the demand for cold chain logistics is becoming more and more vigorous.

However, due to its late start and weak foundation, China's cold chain logistics industry still has some problems, such as incomplete standard system, relatively backward infrastructure, low specialization level, and insufficient effective supervision. The development of cold chain logistics lags behind that of developed countries $[1,2]$. In order to promote the development of cold chain logistics in China, the government should present supportive policies, such as cold chain logistics subsidy, in order to induce enterprises to increase investment in cold chain logistics, and raise the proportion of cold chain processing of agricultural products.

\section{Research Status at Home and Abroad}

With regard to subsidy for cold chain logistics and related research, scholars at home and abroad have made some achievements in this field. Considering the bankruptcy risk in the financing of agricultural enterprises, Huang et al. construct a three-stage Stackelberg game model of government, retailers, and agricultural enterprises on the base of the existing government subsidy mechanism. They propose the government subsidy mechanism to maximize social welfare, and analyze the influence of government subsidy on the interests of all participants in supply chain [3]. Xiong et al. construct the profit models of two supply chain organizational modes, apply the freshness loss compensation 
plan of agricultural products to the elastic quantity contract to form a relationship contract, analyze the influence of cold chain facility subsidy mode on the stability of relationship contract in different organizational modes, and propose that choosing the appropriate cold chain facility subsidy mode can improve the freshness level of agricultural products and the farmers' profit, so as to enhance the stability of the supply chain relationship contract of fresh agricultural products [4]. $\mathrm{Li}$ et al. build an evolutionary game model of logistics resource input between suppliers and producers under government supervision. When the input and output of logistics resources of suppliers and producers are constantly changing, a variety of evolutionary stabilization strategies can be obtained. If the free-rider behavior obtains great benefits from the other participants' resource input, it will greatly damp the enthusiasm for cold chain logistics investment of suppliers and producers. It is found that when the punishment or subsidy of the government exceeds the threshold level, the cold chain logistics investment will become the evolutionary stabilization strategy of suppliers and producers [5]. Mancur analyzes the positive external effect of cold chain logistics investment and propose a punishment and subsidy mechanism for the free-rider behavior of the participants in the cold chain [6]. Zhu and Dou build a three-stage game model in green supply chain management with considering product greenness degree and government subsidy. Through the simulation analysis of the three parameters including the subsidy coefficient per unit product, the greenness degree of the final manufacturer's products, and the price of the final manufacturer's products, it provides a reference for the decision-making of the government and the final manufacturer in the green supply chain management. This study adds consumer preference for environmental protection to the model and provides a reference for analyzing the impact of cold chain logistics subsidy mechanism on consumers [7].

The above research focuses on the influence mechanism of cold chain logistics subsidy on the supply chain, including three aspects. Firstly, through the construction of a subsidy mechanism, we can coordinate the interests of participants in the supply chain, so as to maximize social welfare. Secondly, through the design of the subsidy mechanism, we can improve the freshness degree of fresh products and the stability of supply chain relationship. Thirdly, through the design of the subsidy mechanism, members of the fresh product supply chain should be encouraged to invest in the cold chain, including suppliers and producers, so as to avoid free-rider behavior. These studies provide references for the study of the subsidy mechanism of cold chain logistics, but do not consider the preference of consumers.

This paper analyzes the cold chain subsidy mechanism affecting the differential pricing behavior of cold chain agroproducts and ordinary agro-products and studies the influence of cold chain subsidy on the pricing of upstream and downstream members in the supply chain from the perspective of supply chain coordination under the background of coexistence of two kinds of products in the market. This study has reference value for two types of enterprises to formulate their own pricing strategies in practice. On this basis, the reasonable scope of government subsidy is given through calculation, which can provide some theoretical references for the formulation of government subsidy policy.

\section{Problem Description and Model Construction}

3.1. Problem Description. Cold chain agro-products refer to the products which are processed through the cold chain measures adopted by agro-products suppliers in the process of production, transportation, storage, and sale, such as refrigeration and freezing, so as to preserve the freshness of agro-products and improve the quality of agro-products. Ordinary agro-products need operators of agro-products to take the normal temperature measures to preserve the freshness and quality of agro-products in the operation process. Cold chain agro-products suppliers and ordinary agro-products suppliers will not take cold chain measures at the same time due to differences in operating costs and business philosophy. The coexistence of cold chain agroproducts and ordinary agro-products is a common phenomenon in the market. Cold chain agro-products suppliers hope to gain the product quality competitiveness in the agroproducts market through cold chain measures, win the recognition of the public and consumers, and establish a good corporate image. Ordinary agro-products suppliers hope to operate at normal temperatures, avoid high operation costs, and gain competitive advantage through price advantage.

It is presented a supply chain system consisting of two agro-products suppliers including a cold chain agro-products supplier, an ordinary agro-products supplier, and a retailer. Two agro-products suppliers produce the same variety of agricultural products and sell them through the same retailer. In order to encourage the agro-products cold chain operation, the government will subsidize the suppliers of cold chain agro-products. Firstly, this paper studies the cold chain and price decision-making of the two agro-products suppliers and the price decision-making of the agro-products retailer when there is no government subsidy. Then, it studies the influence of government's cold chain subsidy on cold chain and price decision-making of supply chain members. Finally, it analyzes the coordination strategy of the supply chain under centralized decision-making condition.

3.2. Symbol Explanation. The symbols and explanations are described in the following text:

$v_{C}$ : wholesale price of cold chain agro-products. It is a decision variable of the cold chain agro-products suppliers. The agro-products suppliers include various organizations engaged in agricultural production activities such as agricultural companies and farmers.

$v_{O}$ : wholesale price of ordinary agro-products. It is a decision variable of the ordinary agro-products supplier.

$P_{C}$ : retail price of cold chain agro-products. It is a decision variable of the agro-products retailer. 
$P_{O}$ : retail price of ordinary agro-products. It is a decision variable of agro-products retailers.

$\alpha$ : freshness-keeping rate of cold chain agro-products. It is a decision variable of cold chain agro-products suppliers.

$\beta$ : subsidy coefficient of the cold chain agro-products decided by the government.

$\gamma$ : freshness-keeping difficulty coefficient of the cold chain agro-products suppliers.

\subsection{Model Hypothesis}

(1) Assuming that cold chain agro-products and ordinary agro-products can be substituted for each other in basic functions. Both have the same demand function $d(p)$, and $P_{C}>P_{O}, d(p)$ satisfies first-order linear function, which is $q=d(p)=a-b(p), a$ and $b$ are constants, $a, b>0, a$ represents market capacity, and $b$ represents the sensitivity of consumers to price. Consumers check the freshness degree of agricultural products through packaging labels and on-site inspection. Consumers with sufficient payment ability and high freshness degree requirement will not buy ordinary agro-products. There are two types of consumers in the market. One is the consumer who buys cold chain agro-products, and the other is the consumer who buys ordinary agro-products.

Market demand of cold chain agro-products,

$$
q_{C}=d_{C}(p)=a-b p_{C}
$$

Market demand of ordinary agro-products,

$$
q_{O}=d_{O}(p)=b\left(p_{C}-p_{O}\right)
$$

When the prices of cold chain agro-products and ordinary agro-products are equal, the demand for ordinary agro-products is 0 , and ordinary agro-products will withdraw from the market. According to this hypothesis, the demand for cold chain agro-products and ordinary agro-products is shown in Figure 1.

(2) The suppliers of cold chain agro-products take measures such as cold chain transportation, cold chain storage, and sale to improve the freshness-keeping rate of agro-products $\alpha$ and pay the corresponding cost $g(\alpha)$, such as the cost of using refrigerated trucks, refrigerated cabinets, and temperature or humidity control equipment. This cost increases with the increase of freshness-keeping rate. It means $g^{\prime}(\alpha)>0$. The increased speed is accelerating; it means $g^{\prime \prime}(\alpha)>0$. This characteristic is similar to which of $\mathrm{R} \& \mathrm{D}$ cost. Therefore, this paper assumes a quadratic relationship between freshness-keeping cost and freshness-keeping rate, and $g(\alpha)=(1 / 2) \gamma \alpha^{2}$.
(3) In order to improve the freshness degree of agroproducts, the government encourages the suppliers of agro-products to carry out cold chain transportation. In order to subsidize the suppliers of cold chain agro-products directly, the amount of subsidy is related to the freshness-keeping rate of agroproducts. Assume $\beta=\lambda \alpha$ is the subsidy coefficient of per agro-product decided by the government. $\lambda$ is the adjustment factor of the subsidy coefficient.

(4) Assuming that the retailer can buy cold chain agroproducts and ordinary agro-products only through these two suppliers, the suppliers are in the leading position in the supply chain, and the two suppliers have the same status. For the same reason $[8,9]$, it is assumed that the marginal production cost of the agro-products is 0 for convenience of analysis.

\section{Differential Pricing Model Analysis}

4.1. Decentralized Decision-Making without Government Subsidy. In the supply chain of decentralized decisionmaking, the retailer and two suppliers make decisions in the view of their respective profit maximization. $\pi_{C}, \pi_{O}, \pi_{R}$, and $\pi_{S}$, respectively, represent the profit of cold chain agroproducts supplier, ordinary agro-products supplier, the retailer, and supply chain. The superscript $*$ denotes optimum. Therefore, the profit function without government subsidy is as follows:

$$
\begin{aligned}
& \pi_{C}=v_{C}\left(a-b p_{C}\right)-\frac{1}{2} \gamma \alpha^{2}, \\
& \pi_{O}=v_{O} b\left(p_{C}-p_{O}\right), \\
& \pi_{R}=\left(p_{C}-v_{C}\right)\left(a-b p_{C}\right)+b\left(p_{O}-v_{O}\right)\left(p_{C}-p_{O}\right) .
\end{aligned}
$$

In the model without government subsidy, the profit function of cold chain agro-products supplier consists of two parts, the wholesale price from the retailer and cold chain freshness-keeping cost. Stackelberg dynamic game of simultaneous selection takes place between two suppliers and the retailer in the supplier-led supply chain. In the first stage, the cold chain agro-products supplier decides the wholesale price $v_{C}$ and freshness-keeping rate $\alpha$ of cold chain agroproducts. Ordinary agro-products supplier decides wholesale price of ordinary agro-products $v_{O}$. In the second stage, in the condition of given $\left(v_{C}, v_{O}, \alpha\right)$, the retailer chooses the retail prices $\left(P_{C}, P_{O}\right)$ of two products, and backward induction is adopted to find the solution of subgame perfect Nash equilibrium.

Superscript $N$ means without government subsidy. Given the decision $\left(v_{C}, v_{O}, \alpha\right)$ of the two suppliers, the optimization problem of the retailer is given by

$$
\begin{aligned}
& \max _{p_{C}, p_{O}} \pi_{R}^{N}\left(p_{C}, p_{O} \mid v_{C}, v_{O}, \alpha\right) \\
& \quad=\left(p_{C}-v_{C}\right)\left(a-b p_{C}\right)+b\left(p_{O}-v_{O}\right)\left(p_{C}-p_{O}\right) .
\end{aligned}
$$




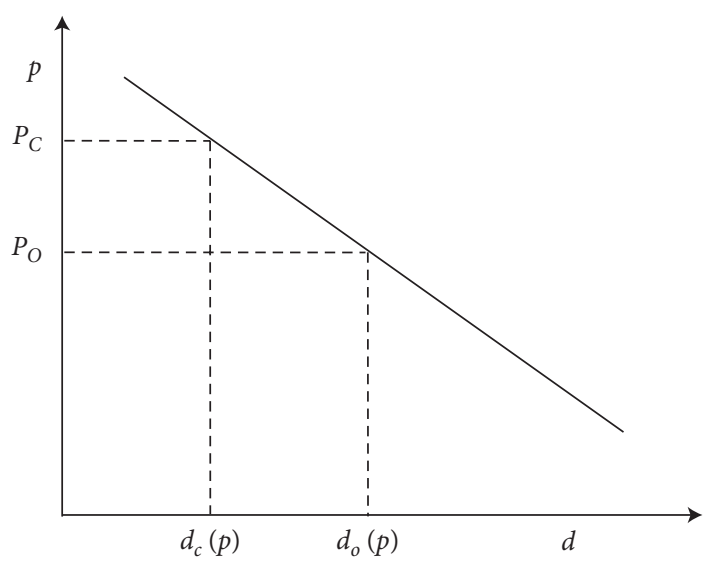

FIgURE 1: Market demand in differential pricing of cold chain agroproducts.

Obviously, $\pi_{R}^{N}\left(p_{C}, p_{O}\right)$ is a joint concave function on $\left(p_{C}, p_{O}\right)$. According to the first-order optimal condition, the retailer's response function can be obtained:

$$
\begin{aligned}
& P_{C}=\frac{2 a+2 b v_{C}-b v_{O}}{3 b}, \\
& P_{O}=\frac{a+b v_{C}+b v_{O}}{3 b} .
\end{aligned}
$$

The response function indicates that the retail price of cold chain agro-products decreases with the increase of the wholesale price of ordinary agro-products, and this is due to the price competition effect. According to the hypothesis (1), the retail price of cold chain agro-products is higher than that of ordinary agro-products. The retailer's response function is substituted into formulae (1) and (2), and we can get

$$
\begin{aligned}
& q_{C}=\frac{a-2 b v_{C}+b v_{O}}{3}, \\
& q_{O}=\frac{a+b v_{C}-2 b v_{O}}{3 b} .
\end{aligned}
$$

Under the price competition effect, the sale volume of cold chain agro-products increases with the increase of the wholesale price of ordinary agro-products and decreases with the increase of their own wholesale price. The same rule exists for ordinary agro-products.

By substituting $q_{C}$ and $q_{O}$ into formula (4), the optimization results of cold chain agro-products supplier and ordinary agro-products supplier can be obtained:

$$
\begin{gathered}
\max _{v_{C}, \alpha} \pi_{C}^{N}\left(v_{C}, \alpha\right)=v_{C} q_{C}-\frac{1}{2} \gamma \alpha^{2}, \\
\max _{v_{O}} \pi_{O}^{N}\left(v_{O}\right)=v_{O} q_{C} .
\end{gathered}
$$

Obviously, $\max _{v_{C}, \alpha} \pi_{C}^{N}\left(v_{C}, \alpha\right)$ is a concave function on $\left(v_{C}, \alpha\right)$, and $\max _{v_{O}} \pi_{O}^{N}\left(v_{O}\right)$ is a concave function on $v_{O}$. From the first-order condition, we can get optimal $\left(v_{C}^{N *}, \alpha^{N *}\right)$ of cold chain agro-products supplier and optimal $v_{O}^{N *}$ of ordinary agro-products supplier. The equilibrium results are shown in Proposition 1.

Proposition 1. Conclusions without government subsidy:

(1) The cold chain agro-products supplier decides the optimal wholesale price and freshness-keeping rate, and the ordinary agro-products supplier decides the optimal wholesale price, $v_{C}^{N *}=(a / 3 b), \alpha^{N *}=0$, and $v_{O}^{N *}=(a / 3 b)$

(2) The retailer decides the optimal retail prices of cold chain agro-products and ordinary agro-products, $p_{C}^{N *}=(7 a / 9 b)$ and $p_{O}^{N *}=(5 a / 9 b)$

(3) The sale volumes of cold chain agro-products and ordinary agro-products are as follows: $q_{C}^{N *}=(2 a / 9)$ and $q_{O}^{N *}=(2 a / 9)$

(4) The profit of cold chain agro-products supplier, ordinary agro-products supplier, retailer, and supply chain is $\pi_{C}^{N *}=\left(2 a^{2} / 27 b\right), \quad \pi_{O}^{N *}=\left(2 a^{2} / 27 b\right)$, $\pi_{R}^{N *}=\left(4 a^{2} / 27 b\right)$, and $\pi_{S}^{N *}=\left(8 a^{2} / 27 b\right)$, respectively.

According to Proposition 1, because of the freshnesskeeping cost, the freshness-keeping rate of cold chain agroproducts supplier without government subsidy $\alpha^{N *}$ is 0 , and the market is divided equally by the two kinds of products, $q_{C}^{N *}=q_{O}^{N *}$. The government needs to take measures such as cold chain subsidy to promote the cold chain business of agroproducts suppliers.

4.2. Decentralized Decision-Making with Government Subsidy. When the government directly subsidizes the coldchain agro-products supplier, the profit function of cold chain agro-products supplier, ordinary agro-products supplier, and the retailer is, respectively, as follows:

$$
\begin{aligned}
& \pi_{C}=\left(v_{C}+\lambda \alpha\right)\left(a-b p_{C}\right)-\frac{1}{2} \gamma \alpha^{2}, \\
& \pi_{O}=v_{O} b\left(p_{C}-p_{O}\right), \\
& \pi_{R}=\left(p_{C}-v_{C}\right)\left(a-b p_{C}\right)+b\left(p_{O}-v_{O}\right)\left(p_{C}-p_{O}\right) .
\end{aligned}
$$

The profit of cold chain agro-products supplier consists of three parts: wholesale price $v_{C}\left(a-b p_{C}\right)$, freshnesskeeping subsidy $\lambda \alpha\left(a-b p_{C}\right)$ from the government, and freshness-keeping cost (1/2) $\gamma \alpha^{2}$. The profit structure of supplier and retailer of ordinary agro-products does not change. The optimal decision strategy $\left(v_{C}, v_{O}, \alpha\right)$ of two suppliers is presented, superscript $B$ represents government subsidy, and the optimal solution of the retailer is as follows:

$$
\begin{aligned}
& \max _{p_{C}, p_{O}} \pi_{R}^{B}\left(p_{C}, p_{O} \mid v_{c}, v_{o}, \alpha\right) \\
& \quad=\left(p_{C}-v_{c}\right)\left(a-b p_{C}\right)+b\left(p_{O}-v_{O}\right)\left(p_{C}-p_{O}\right) .
\end{aligned}
$$

Obviously, $\pi_{R}^{B}\left(p_{C}, p_{O}\right)$ is a joint concave function on $\left(p_{C}, p_{O}\right)$, and according to the first-order optimal condition, the retailer's response function can be obtained: 


$$
\begin{aligned}
& P_{C}\left(v_{C}, v_{O}, \alpha\right)=\frac{2 a+2 b v_{C}-b v_{O}}{3 b}, \\
& P_{O}\left(v_{C}, v_{O}, \alpha\right)=\frac{a+b v_{C}+b v_{O}}{3 b} .
\end{aligned}
$$

By substituting the retailer's response function into formulae (13) and (14), the optimal solutions of cold chain agro-products supplier and ordinary agro-products supplier can be obtained, respectively:

$$
\begin{aligned}
\max _{v_{C}, \alpha} \pi_{C}\left(v_{C}, \alpha\right) & =\left(v_{C}+\lambda \alpha\right)\left(a-b p_{C}\right)-\frac{1}{2} \gamma \alpha^{2}, \\
\max _{v_{O}} \pi_{O}\left(v_{O}\right) & =v_{O} b\left(p_{C}-p_{O}\right) .
\end{aligned}
$$

When $3 \gamma>b \lambda^{2}, \max _{v_{C}, \alpha} \pi_{C}^{B}\left(v_{C}, \alpha\right)$ is a concave function on $\left(v_{C}, \alpha\right) \cdot \max _{v_{O}} \pi_{O}^{B}\left(v_{O}\right)$ is a concave function on $v_{O}$. From the first-order condition, we can obtain the optimal solution $\left(v_{C}^{B *}, \alpha^{B *}\right)$ of cold chain agro-products supplier and obtain the optimal solution $v_{O}^{B *}$ of ordinary agro-products supplier. The equilibrium results are shown in Proposition 2.

Proposition 2. When the government presents cold chain subsidy policy, the following conclusions are drawn:

(1) The optimal freshness-keeping rate decided by cold chain agro-products supplier is greater than 0 , and the wholesale prices of cold chain agro-products and ordinary agro-products are lower than those without government subsidy:

$$
\begin{aligned}
v_{C}^{B *} & =\frac{5 a\left(3 \gamma-2 b \lambda^{2}\right)}{b\left(45 \gamma-14 b \lambda^{2}\right)}<v_{C}^{N *}, \\
\alpha^{B *} & =\frac{10 a \lambda}{45 \gamma-14 b \lambda^{2}}>0, \\
v_{O}^{B *} & =\frac{3 a\left(5 \gamma-2 b \lambda^{2}\right)}{b\left(45 \gamma-14 b \lambda^{2}\right)}<v_{O}^{N *} .
\end{aligned}
$$

(2) The optimal retail prices of cold chain agro-products and ordinary agro-products with government subsidy are lower than the retail prices without government subsidy:

$$
\begin{aligned}
& p_{C}^{B *}=\frac{\left.35 a \gamma-14 a b \lambda^{2}\right)}{b\left(45 \gamma-14 b \lambda^{2}\right)}<p_{C}^{N *}, \\
& p_{O}^{B *}=\frac{25 a \gamma-10 a b \lambda^{2}}{b\left(45 \gamma-14 b \lambda^{2}\right)}<p_{O}^{N *} .
\end{aligned}
$$

(3) The sale volume of cold chain agro-products with government subsidy is larger than that without government subsidy, while the sale volume of ordinary agro-products is the opposite:

$$
\begin{aligned}
& q_{C}^{B *}=\frac{10 a \gamma}{\left.45 \gamma-14 b \lambda^{2}\right)}>q_{C}^{N *}, \\
& q_{O}^{B *}=\frac{10 a \gamma-4 a b \lambda^{2}}{\left.45 \gamma-14 b \lambda^{2}\right)}<q_{O}^{N *} .
\end{aligned}
$$

(4) The profit of cold chain agro-products supplier, ordinary agro-products supplier, the retailer, and supply chain is compared with those in decentralized decision-making condition, and the results are as follows:

$$
\begin{aligned}
& \pi_{C}^{B *}=\frac{50 a^{2} \gamma\left(3 \gamma-b \lambda^{2}\right)}{b\left(45 \gamma-14 b \lambda^{2}\right)^{2}}>\pi_{C}^{N *}, \\
& \pi_{O}^{B *}=\frac{6 a^{2}\left(25 \gamma^{2}-20 b \gamma \lambda^{2}+4 b^{2} \lambda^{2}\right)}{b\left(45 \gamma-14 b \lambda^{2}\right)^{2}}<\pi_{O}^{N *}, \\
& \pi_{R}^{B *}=\frac{4 a^{2}\left(75 \gamma^{2}-30 b \gamma \lambda^{2}+4 b^{2} \lambda^{2}\right)}{b\left(45 \gamma-14 b \lambda^{2}\right)^{2}}>\pi_{R}^{N *}, \\
& \pi_{S}^{B *}=\frac{10 a^{2}\left(60 \gamma^{2}-29 b \gamma \lambda^{2}+4 b^{2} \lambda^{2}\right)}{b\left(45 \gamma-14 b \lambda^{2}\right)^{2}}>\pi_{S}^{N *} .
\end{aligned}
$$

According to Proposition 2, the following corollaries are obtained.

\section{Corollary 1}

(1) We have

$$
\begin{aligned}
& \frac{\delta \alpha^{B *}}{\delta \lambda}=\frac{10 a}{45 \gamma-14 b \lambda^{2}}+\frac{280 a b \lambda^{2}}{\left(45 \gamma-14 b \lambda^{2}\right)^{2}}>0, \\
& \frac{\delta \alpha^{B *}}{\delta \gamma}=\frac{-450 a \lambda}{\left(45 \gamma-14 b \lambda^{2}\right)^{2}}<0 .
\end{aligned}
$$

(2) We have

$$
q_{C}^{B *}-q_{O}^{B *}=\frac{4 a b \lambda^{2}}{45 \gamma-14 b \lambda^{2}}>0
$$

From Proposition 2 and Corollary 1, (1) under the government subsidy policy, the cold chain agro-products supplier begins to implement the cold chain freshness-keeping operation. The freshness-keeping rate is positively correlated with $\lambda$, the adjustment factor of government subsidy coefficient, and negatively correlated with $\gamma$, the difficulty coefficient of freshness-keeping. This is because the adjustment factor of government subsidy coefficient directly affects the profit of cold chain agro-products supplier. The higher the freshness-keeping rate is, the more subsidies the government provides. Freshness- 
keeping difficulty coefficient directly affects the cost of cold chain agro-products supplier. The bigger the difficulty coefficient, the higher the freshness-keeping cost, the more reluctant the agro-products supplier is to improve the freshnesskeeping rate. In addition, because the freshness-keeping rate of cold chain agro-products supplier cannot exceed 1, and therefore, the government should decide the subsidy scope according to the condition $0<\alpha^{B *}<1$, when they formulate the subsidy policy. In the decentralized system with government subsidy, the reasonable scope of subsidy is $0<\lambda<\left(\left(\sqrt{5\left(5 a^{2}+126 b \gamma\right)}-5 a\right) / 14 b\right)$. When $\lambda \leq 0$, enterprises will not have the motivation to implement cold chain operation.

When $\lambda>\left(\left(\sqrt{5\left(5 a^{2}+126 b m\right)}-5 a\right) / 14 b\right)$, the excess subsidy provided by the government no longer improves the freshness-keeping rate. (2) The government subsidizes the cold chain agro-products supplier, which not only reduces the wholesale price and retail price of cold chain agroproducts, but also reduces the wholesale price and retail price of ordinary agro-products due to the existence of price competition between two kinds of agro-products. (3) After subsidy, the cold chain agro-products supplier gains the greater price advantage, and their market share increases correspondingly, while the market share of ordinary agroproducts decreases correspondingly. The final result is that the market share of cold chain agro-products supplier is larger than that of ordinary agro-products. In view of the above, we can know that the government can effectively control the proportion of cold-chain agro-products and ordinary agro-products in the market by means of subsidy policy. (4) The government subsidy for cold chain agroproducts not only increases the profit of cold chain agroproducts supplier, but also increases the profits of the retailer and the whole supply chain due to the sale increase of cold chain agro-products. Only the profit of ordinary agroproducts supplier decreases after the subsidy.

This shows that the increase of the overall supply chain profit caused by the increase of the cold chain agro-products market share exceeds the decrease of the profit of the overall supply chain caused by the decrease of the ordinary agroproducts market share.

\subsection{Centralized Decision-Making with Government Subsidy.} In the market economy system, if the upstream and downstream enterprises of supply chain belong to different economic entities, respectively, there is no central decision-maker aiming at maximizing the benefit of the overall supply chain. However, the optimal decision-making in the centralized decision-making system can be used as a benchmark to study the effect of contract coordination. Articles such as Cachon and Zhang assume that the upstream and downstream of the supply chain are vertically integrated, and the profit maximization of the supply chain is used as a benchmark to study the coordination of the supply chain $[10,11]$. In the centralized decision-making system, it is assumed that there is a central decision-maker whose decision variables are $P_{L}, P_{H}$, and $\tau$, superscript $C$ represents centralized decision-making.
Therefore, in the centralized decision-making system with government subsidy, the optimization solution is given by

$$
\max _{p_{C}, p_{0}, \alpha} \pi_{I}^{C}=\left(p_{C}+\lambda \alpha\right)\left(a-b p_{C}\right)+p_{O} b\left(p_{C}-p_{O}\right)-\frac{1}{2} \gamma \alpha^{2} .
$$

According to the Hesse matrix, when $3 \gamma>b \lambda^{2}$, $\max _{p_{C}, p_{O}, \alpha} \pi_{I}^{C}$ is a joint concave function on $P_{C}, P_{O}, \alpha$. Make use of the first-order condition of $P_{C}, P_{O}$, and $\alpha$, we can figure out $p_{C}^{C *}, p_{O}^{C *}$, and $\alpha^{C *}$, superscript $C^{*}$ denotes the optimal result, and the equilibrium result is shown in Proposition 3.

Proposition 3. In the centralized decision-making system with government subsidy, the following conclusions are drawn:

(1) The retail price of cold chain agro-products and the retail price of ordinary agro-products are the lowest in the centralized decision-making system with government subsidy:

$$
\begin{aligned}
& p_{C}^{C *}=\frac{2 a\left(\gamma-b \lambda^{2}\right)}{b\left(3 \gamma-2 b \lambda^{2}\right)}<p_{C}^{B *}<p_{C}^{N *}, \\
& p_{O}^{C *}=\frac{a\left(\gamma-b \lambda^{2}\right)}{b\left(3 \gamma-2 b \lambda^{2}\right)}<p_{O}^{B *}<p_{O}^{N *} .
\end{aligned}
$$

(2) The freshness-keeping rate of cold chain agro-products is the highest in the centralized decision-making system with government subsidy:

$$
\alpha^{C *}=\frac{a \lambda}{3 \gamma-2 b \lambda^{2}}>\alpha^{B *}>\alpha^{N *} .
$$

(3) In the centralized decision-making system with government subsidy, the sale volume of cold chain agroproducts is the largest, and the sale volume of ordinary agro-products is higher than that of the decentralized decision-making system:

$$
\begin{aligned}
& q_{C}^{C *}=\frac{a \gamma}{3 \gamma-2 b \lambda^{2}}>q_{C}^{B *}>q_{C}^{N *}, \\
& q_{O}^{C *}=\frac{a \gamma-a b \lambda^{2}}{3 \gamma-2 b \lambda^{2}}>q_{O}^{B *} .
\end{aligned}
$$

(4) The profit of the overall supply chain in the centralized decision-making system with government subsidy is as follows:

$$
\pi_{I}^{C 2}=\frac{6 a^{2} \gamma^{2}-7 a^{2} b \gamma \lambda^{2}+2 a^{2} b^{2} \lambda^{4}}{2 b\left(3 \gamma-2 b \lambda^{2}\right)^{2}} .
$$

Proposition 3 shows that there is only one decisionmaker which can eliminate the "double marginalization effect," and the retail prices of cold chain agro-products and ordinary agro-products are the lowest, while the freshnesskeeping rate of cold chain agro-products is the highest at this time. In addition, according to $0<\alpha^{B *}<1$, the scope of 
subsidy decided by the government, the reasonable subsidy in centralized decision-making system is as follows:

$$
\begin{aligned}
0 & <\lambda<\left(\frac{\sqrt{a^{2}+24 b \gamma}-a}{14 b}\right), \\
\left(\frac{\sqrt{a^{2}+24 b \gamma}-a}{4 b b}\right) & <\frac{\sqrt{5\left(5 a^{2}+126 b \gamma\right)}-5 a}{14 b} .
\end{aligned}
$$

Therefore, in the centralized decision-making system, the government can get the better subsidy effect by subsidizing enterprises.

The abovementioned content analyzes the differential pricing decision and cold chain decision of cold chain agroproducts and ordinary agro-products under the three models. Through the comparative analysis of the three models, it is found that, compared with the nongovernment subsidy, the price of cold chain agro-products decreases, the freshness-keeping rate increases, and the profit and market share also increase in the condition of the government subsidy. Therefore, government subsidy can play a positive role in encouraging agro-products suppliers to implement cold chain freshness-keeping operation. By comparing the centralized and decentralized decision-making system with government subsidy, the centralized decision-making system eliminates the "double marginalization effect." The retail price of agro-products is low and the profit of the overall supply chain is optimal.

Therefore, both cold chain agro-products supplier and ordinary agro-products supplier have the motivation to design an incentive mechanism of coordinating the supply chain to achieve the optimal effect of centralized decisionmaking. The retailer sets a retail price in the condition of centralized decision-making. The supplier of cold chain agro-products decides the optimal freshness-keeping rate in accordance with the freshness-keeping rate of centralized decision-making. The principle of win-win is adopted to ensure the participation and restraint of all participants involved in cooperation.

\section{Supply Chain Coordination Based on Shapley Value Method}

5.1. Introduction of Shapley Value Method. From the above analysis, we know that noncooperative decentralized decision-making leads to "double marginalization effect" which will reduce the profit of the whole supply chain. In order to protect the benefit of supply chain from loss, the coordination of the supply chain should be considered.

Shapley value method fairly and effectively distributes the benefit among the alliance members according to their contribution [12]. The basic principle of the Shapley value method is as follows: $I=\{1,2, \ldots, n\}$ denotes the aggregation of all players, and $z$ denotes an alliance, that is, in a multiplayer game, some players unite to choose strategies like one player, which is called alliance. Obviously, alliance $z$ is a subset of the set $I$ of players, $z \subseteq I$.

When several players unite to form an alliance $z$, they can obtain the maximum return value in this game, $v(z)$, if the revenue function $v(z)$ satisfies the following equation:

$$
\begin{aligned}
v(\phi) & =0, \\
v\left(z_{1} \cup z_{2}\right) \geq v\left(z_{1}\right)+v\left(z_{2}\right), z_{1} \cap z_{2} & =\phi,
\end{aligned}
$$

where $v(z)$ is defined as a characteristic function of $I$ and represents the benefit of cooperation alliance $z$. The above two formulas embody the system thought of " $1+1>2$ " and satisfy the superadditivity, which means that their interests are the greatest and the maximum benefit of cooperation is $v(I)$ when players cooperate.

Let $\mu_{i}(i=1,2, \ldots, n)$ denote the benefit of member $i$ of $I$ from the maximum benefit of cooperation $v(I)$, then the distribution of the maximum benefit of cooperation can be described as $\mu(v)=\left(\mu_{1}(v), \mu_{2}(v), \ldots, \mu_{n}(v)\right)$. At the same time, the following requirements need to be satisfied:

$$
\sum_{i=1}^{n} \mu_{i}(v)=v(I) \mu_{i}(v)>v(i), \quad i=1,2, \ldots, n .
$$

When all members of $I$ choose to cooperate, the Shapley value of benefit distribution among the members of the supply chain is given by

$$
\begin{aligned}
\mu_{i}(v) & =\sum_{i \in z(i)} w(z)[v(z)-v(z \backslash i)], \quad i=1,2, \ldots, n, \\
w(|z|) & =\frac{(n-|z|) !(|z|-1) !}{n !}
\end{aligned}
$$

where $z(i)$ denotes all subsets of set $I$ which contain player $i$, $|z|$ is the number of elements in the subset $z, n$ is the number of elements in the set $I$, and $w(|z|)$ is the weighting factor; it is the probability that the players make a contribution to the alliance. $v(z)$ represents the benefit of subset $z$, and $v(z \backslash i)$ is the benefit of subset $z$ removing player $i$.

5.2. Partial Alliance. When the cold chain agro-products supplier and ordinary agro-products supplier build an alliance,

$$
\begin{gathered}
\max _{p_{C}, p_{O}, \alpha} \pi_{C O}=\left(v_{C}+\lambda \alpha\right)\left(a-b p_{C}\right)+v_{O} b\left(p_{C}-p_{O}\right)-\frac{1}{2} \gamma \alpha^{2} \\
\text { s.t. } \max _{p_{C}, p_{O}} \pi_{R}=\left(p_{C}-v_{C}\right)\left(a-b p_{C}\right)+\left(p_{O}-v_{O}\right) b\left(p_{C}-p_{O}\right) .
\end{gathered}
$$

Solution available: 


$$
\begin{aligned}
v_{C}^{*} & =\frac{3 a\left(2 \gamma-b \lambda^{2}\right)}{4 b\left(3 \gamma-b \lambda^{2}\right)}, \\
v_{O}^{*} & =\frac{a}{2 b}, \\
\alpha^{*} & =\frac{a \lambda}{2\left(3 \gamma-b \lambda^{2}\right)}, \\
p_{C}^{*} & =\frac{5 a \gamma-2 a b \lambda^{2}}{2 b\left(3 \gamma-b \lambda^{2}\right)}, \\
p_{O}^{*} & =\frac{8 a \gamma-3 a b \lambda^{2}}{4 b\left(3 \gamma-b \lambda^{2}\right)}, \\
\pi_{C O}^{*} & =\left(v_{C}^{*}+\lambda \alpha^{*}\right)\left(a-b p_{C}^{*}\right)+v_{O}^{*} b\left(p_{C}^{*}-p_{O}^{*}\right)-\frac{1}{2} \gamma \alpha^{* 2} .
\end{aligned}
$$

When the cold chain agro-products supplier and the retailer build an alliance,

$$
\begin{aligned}
\max _{p_{C}, p_{O}, \alpha} \pi_{C R}= & \left(p_{C}+\lambda \alpha\right)\left(a-b p_{C}\right)+\left(p_{O}-v_{O}\right) b\left(p_{C}-p_{O}\right) \\
& -\frac{1}{2} \gamma \alpha^{2} \\
\text { s.t. } \max _{v_{O}} \pi_{O}= & v_{O} b\left(p_{C}-p_{O}\right) .
\end{aligned}
$$

Solution available:

$$
\begin{aligned}
& w_{O}^{*}=\frac{a\left(\gamma-b \lambda^{2}\right)}{2 b\left(2 \gamma-b \lambda^{2}\right)}, \\
& \alpha^{*}=\frac{a \lambda\left(5 \gamma-3 b \lambda^{2}\right)}{2\left(3 \gamma-2 b \lambda^{2}\right)\left(2 \gamma-b \lambda^{2}\right)}, \\
& p_{C}^{*}=\frac{\left(a \gamma-a b \lambda^{2}\right)\left(7 \gamma-4 b \lambda^{2}\right)}{2 b\left(3 \gamma-2 b \lambda^{2}\right)\left(2 \gamma-b \lambda^{2}\right)} \\
& p_{O}^{*}=\frac{\left(a \gamma-a b \lambda^{2}\right)\left(3 \gamma-b \lambda^{2}\right)}{2 b\left(3 \gamma-2 b \lambda^{2}\right)\left(2 \gamma-b \lambda^{2}\right)}, \\
& \pi_{C R}^{*}=\left(p_{C}^{*}+\lambda \tau^{*}\right)\left(a-b p_{C}^{*}\right)+\left(p_{O}^{*}-v_{O}^{*}\right) b\left(p_{C}^{*}-p_{O}^{*}\right)-\frac{1}{2} \gamma \alpha^{* 2} .
\end{aligned}
$$

When the ordinary agro-products supplier and the retailer build an alliance,

$$
\begin{aligned}
& \max _{p_{C}, p_{O}} \pi_{O R}=\left(p_{C}-w_{C}\right)\left(a-b p_{C}\right)+p_{O} b\left(p_{C}-p_{O}\right), \\
& \max _{v_{C}, \alpha} \pi_{C}=\left(v_{C}+\lambda \alpha\right)\left(a-b p_{C}\right)-\frac{1}{2} \gamma \alpha^{2} .
\end{aligned}
$$

Solution available:

$$
\begin{aligned}
& v_{C}^{*}=\frac{a\left(3 \gamma-2 b \lambda^{2}\right)}{4 b\left(3 \gamma-b \lambda^{2}\right)}, \\
& \alpha^{*}=\frac{a \lambda}{2\left(3 \gamma-2 b \lambda^{2}\right)}, \\
& p_{C}^{*}=\frac{2 a}{3 b}+\frac{a\left(3 \gamma-2 b \lambda^{2}\right)}{6 b\left(3 \gamma-b \lambda^{2}\right)}, \\
& p_{O}^{*}=\frac{a}{3 b}+\frac{a\left(3 \gamma-2 b \lambda^{2}\right)}{12 b\left(3 \gamma-b \lambda^{2}\right)}, \\
& \pi_{O R}^{*}=\left(p_{C}^{*}-v_{C}^{*}\right)\left(a-b p_{C}^{*}\right)+p_{O}^{*} b\left(p_{C}^{*}-p_{O}^{*}\right),
\end{aligned}
$$

According to Table 1, the benefit distribution of the cold chain agro-products supplier is as follows:

$$
\mu_{C}^{*}(v)=\frac{1}{3} \pi_{C}^{*}+\frac{1}{6}\left[\pi_{C O}^{*}-\pi_{O}^{*}\right]+\frac{1}{6}\left[\pi_{C R}^{*}-\pi_{R}^{*}\right]+\frac{1}{3}\left[\pi_{C O R}^{*}-\pi_{O R}^{*}\right] .
$$

For the same reason, the benefit distribution between the ordinary agro-products supplier and the retailer is as follows:

$$
\begin{aligned}
& \mu_{O}^{*}(v)=\frac{1}{3} \pi_{O}^{*}+\frac{1}{6}\left[\pi_{C O}^{*}-\pi_{O}^{*}\right]+\frac{1}{6}\left[\pi_{O R}^{*}-\pi_{R}^{*}\right]+\frac{1}{3}\left[\pi_{C O R}^{*}-\pi_{C R}^{*}\right], \\
& \mu_{R}^{*}(v)=\frac{1}{3} \pi_{R}^{*}+\frac{1}{6}\left[\pi_{C R}^{*}-\pi_{C}^{*}\right]+\frac{1}{6}\left[\pi_{O R}^{*}-\pi_{O}^{*}\right]+\frac{1}{3}\left[\pi_{C O R}^{*}-\pi_{C O}^{*}\right] .
\end{aligned}
$$

The decentralized decision-making supply chain sets the price and decides the freshness-keeping rate based on $\left(p_{C}^{D *}, p_{O}^{D *}, \alpha^{D *}\right)$ and then redistributes the profit through Shapley value method. The profit distribution means $\left(\mu_{C}^{*}(v)\right.$, $\left.\mu_{O}^{*}(v) \mu_{R}^{*}(v)\right)$ and finally achieves supply chain coordination.

\section{Numerical Example}

Set $a=50, b=6, \gamma=150$, and $\lambda=2$. Contrast the profit of each member in the supply chain with government subsidy and the one without government subsidy, and use the Shapley value method to coordinate each member in the supply chain with government subsidy, as shown in Table 2 . Table 2 shows that (1) compare the profit distribution of the decentralized decision-making with government subsidy with the one without government subsidy, the profit of supplier and retailer and the profit of overall supply chain of cold chain agro-products all increase, while the profit of ordinary agro-products supplier decreases. This is because the government subsidy strengthens the price advantage of cold chain agro-products and indirectly weakens the competitiveness of ordinary agro-products, so that the profit of ordinary agro-products supplier decreases, which is conducive to the government's control of cold chain agroproducts and ordinary agro-products. (2) In the condition of government subsidy, after coordination on profit distribution in the case of the centralized decision-making by means of Shapley value method, the profit of each member in the 
TABLE 1: Calculation of Shapley value of cold chain agro-products supplier.

\begin{tabular}{lcccc}
\hline$z$ & $C$ & $C O$ & $C R$ & $C O R$ \\
\hline$v(z)$ & $\pi_{C}^{*}$ & $\pi_{C O}^{*}$ & $\pi_{C R}^{*}$ & $\pi_{C O R}^{*}$ \\
$v(z \backslash C)$ & 0 & $\pi_{O}^{*}$ & $\pi_{C R}^{*}$ & $\pi_{O R}^{*}$ \\
$v(s)-v(z \backslash C)$ & $\pi_{C}^{*}$ & $\pi_{C O}^{*}-\pi_{O}^{*}$ & 2 & $\pi_{C O R}^{*}-\pi_{O R}^{*}$ \\
$|z|$ & 1 & 2 & $1 / 6$ & 3 \\
$v(|z|)$ & $1 / 3$ & $(1 / 6)\left[\pi_{C O}^{*}-\pi_{O}^{*}\right]$ & $(1 / 6)\left[\pi_{C R}^{*}-\pi_{R}^{*}\right]$ & $(1 / 3)\left[\pi_{C O R}^{*}-\pi_{O R}^{*}\right]$ \\
$v(|z|)[v(z)-v(z \backslash C)]$ & $(1 / 3) \pi_{C}^{*}$ & &
\end{tabular}

TABLE 2: Comparison of profits of members in supply chain in various conditions.

\begin{tabular}{|c|c|c|c|c|}
\hline Decision-making types under subsidy policy & $\pi_{C}^{*}$ & $\pi_{O}^{*}$ & $\pi_{R}^{*}$ & Gross profit \\
\hline Decentralized decision-making without government subsidy & 30.86 & 30.86 & 61.73 & 123.46 \\
\hline Decentralized decision-making with government subsidy & 32.36 & 29.95 & 64.08 & 126.39 \\
\hline Centralized decision-making coordination with government subsidy & 35.27 & 34.92 & 72.85 & 143.03 \\
\hline
\end{tabular}

TABLE 3: Sensitivity analysis of parameters.

\begin{tabular}{|c|c|c|c|c|c|c|c|}
\hline \multirow{2}{*}{\multicolumn{2}{|c|}{$\begin{array}{l}\text { Parameter } \\
\text { value }\end{array}$}} & \multicolumn{6}{|c|}{ Optimal value } \\
\hline & & $\begin{array}{l}\text { Retail price of cold } \\
\text { chain products } p_{C}^{D *}\end{array}$ & $\begin{array}{c}\text { Retail price of } \\
\text { common products } \\
p_{O}^{D *}\end{array}$ & $\begin{array}{c}\text { Fresh-keeping rate of } \\
\text { cold chain products (\%) } \\
\alpha^{D *}\end{array}$ & $\begin{array}{c}\text { Profit of cold } \\
\text { chain supplier } \pi_{C}^{*}\end{array}$ & $\begin{array}{l}\text { Profit of common } \\
\text { product supplier } \pi_{O}^{*}\end{array}$ & $\begin{array}{c}\text { Retailer } \\
\text { profit } \pi_{R}^{*}\end{array}$ \\
\hline \multirow{3}{*}{$\lambda$} & 1 & 5.48 & 2.74 & 11.42 & 32.76 & 37.08 & 70 \\
\hline & 2 & 5.22 & 2.61 & 24.88 & 35.27 & 34.92 & 72.85 \\
\hline & 3 & 4.68 & 2.34 & 43.86 & 40.19 & 31.13 & 78.53 \\
\hline \multirow{3}{*}{$\gamma$} & 100 & 5.03 & 2.51 & 39.68 & 37.11 & 33.43 & 74.96 \\
\hline & 150 & 5.22 & 2.61 & 24.88 & 35.27 & 34.92 & 72.85 \\
\hline & 200 & 5.31 & 2.66 & 18.11 & 34.40 & 35.65 & 71.86 \\
\hline \multirow{3}{*}{$a$} & 30 & 3.13 & 1.57 & 14.93 & 12.7 & 12.57 & 26.22 \\
\hline & 50 & 5.22 & 2.61 & 24.88 & 35.27 & 34.92 & 72.85 \\
\hline & 70 & 7.31 & 3.66 & 34.83 & 69.13 & 68.44 & 142.78 \\
\hline \multirow{3}{*}{$b$} & 5 & 6.34 & 3.17 & 24.39 & 41.63 & 42.49 & 86.62 \\
\hline & 6 & 5.22 & 2.61 & 24.88 & 35.27 & 34.92 & 72.85 \\
\hline & 7 & 4.42 & 2.21 & 25.38 & 30.74 & 29.51 & 63.03 \\
\hline
\end{tabular}

supply chain is greater than the one in the decentralized decision-making system, which satisfies the participation constraints of each member in the supply chain and meanwhile optimizes the profit of the whole supply chain.

In addition, the influence of the difficulty coefficient of freshness-keeping and the adjustment coefficient of government subsidy on decision variables and profits are shown in Table 3.

According to Table 3,

(1) With the increase of government subsidy, the retail prices of cold chain agro-products and ordinary agro-products will decrease, the freshness-keeping rate of cold chain agro-products will increase, the profits of cold chain agro-products supplier and retailer will increase, and the profit of ordinary agroproducts supplier will decrease. According to these characteristics, the government indirectly controls the freshness-keeping rate of cold chain agroproducts, meanwhile, it also achieves the goal of improving the enthusiasm of cold chain agroproducts supplier and retailer to produce or sell cold chain agro-products. This is the main reason why the government makes policy subsidizing cold chain agro-products.

(2) With the increasing freshness-keeping difficulty of cold chain agro-products, the freshness-keeping rate of cold chain agro-products decreases, the retail prices of cold chain agro-products and ordinary agro-products increase, and the profits of cold chain agro-products supplier and retailer decrease. Only the profit of ordinary agro-products supplier increases. This is because the more difficult it is to keep freshness, the higher the cost that the cold chain agro-products supplier pays for keeping freshness, which leads to the increase of wholesale price and retail price of cold chain agro-products, and the increase of prices leads to the decrease of sale volume and ultimately leads to the decrease of profits of both cold chain agro-products supplier and retailer. At this time, due to the relative price advantage of ordinary agro-products, ordinary agro-products supplier gets more profit. This is the main reason that the difficulty of keeping freshness restricts the cold chain operation. 
(3) With the increase of market capacity, the retail prices of two kinds of agro-products, the freshness-keeping rate of cold chain agro-products, and the profit of each member in the supply chain increase. This is the result of the interaction between supply and demand in the market and conforms to the market rules.

(4) The more sensitive the consumers are to prices, the lower the retail prices of both kinds of agro-products and the lower the profit of each member in the supply chain. This sensitivity can be evaluated to provide a reference for making price [13]. If we want to improve the profit of each member in the supply chain, we need to use nonprice characteristics to change consumers' price sensitivity.

\section{Conclusion and Prospect}

In view of the policy support of the government's cold chain subsidy and consumers' increasing preference for cold chain keeping freshness, more and more agro-products enterprises implement cold chain operation. It is a remarkable characteristic of the market that the same variety of agro-products implements cold chain operation and ordinary operation in the market at the same time. Based on this, this paper chooses the supply chain system composed of cold chain agro-products supplier, ordinary agroproducts supplier, and retailer as the research object, studies the differential pricing strategies of supply chain members, introduces government subsidy to indirectly reduce the cost of cold chain agro-products, and builds a differential pricing model for upstream and downstream members in supply chain with government subsidy. By solving the model and comparing it with the one with centralized decision-making, the following conclusions are found. First of all, the government subsidy policy can reduce the wholesale price and retail price of cold chain agroproducts and ordinary agro-products at the same time; however, cold chain agro-products have greater competitive advantages because of being backed by government subsidy, and market share will increase correspondingly and ultimately lead to the increase of profits of supplier and retailer of cold chain agro-products. This also indirectly shows that government subsidy for cold chain agroproducts can promote the development of cold chain agroproducts. In addition, through calculation, we can find that the government subsidy policy has a certain scope of validity, and only in this scope can the subsidy policy play an active role in promoting cold chain business. This conclusion can provide a theoretical basis for the formulation of government policy. Secondly, by comparing with centralized decision-making, it is found that although the government subsidy policy can improve the competitiveness of cold chain agro-products and increase the profit of cold chain agro-products supplier and supply chain system, the decentralized decision-making cannot coordinate the supply chain, which results in the loss of supply chain efficiency. In view of the loss of supply chain efficiency caused by decentralized decision-making, this paper chooses Shapley value method with strong operability and good stability to coordinate the supply chain. After coordination, the efficiency of supply chain can be improved to achieve the effect of centralized decision-making. This conclusion can provide theoretical guidance for joint pricing in practice. Finally, a numerical example is given to validate the proposition in this paper, and sensitivity analysis is made on the adjustment factor of government subsidy coefficient, the freshness-keeping difficulty coefficient, market capacity, and consumer price sensitivity.

This paper focuses on the cold chain operation management and pricing decision-making of enterprises with the government's cold chain subsidy. The government's cold chain subsidy is related to the freshness-keeping rate of enterprises. The higher the freshness-keeping rate, the more the cold chain subsidy provided by the government. The government subsidy plays a role in encouraging enterprises to implement cold chain operation and improving freshness-keeping rate. However, there is no specific target of freshness-keeping rate in the text. In the future, it will be one of our further research directions to add the target of freshness-keeping rate and cold chain efficiency when the government formulates the cold chain policy. In addition, the impact of the supply chain network structure on the mechanism of cold chain logistics subsidy is also worthy of consideration [14-16].

\section{Data Availability}

The data used to support the findings of the study are available within the article.

\section{Conflicts of Interest}

The authors declare no conflicts of interest regarding the content and implications of this manuscript.

\section{Acknowledgments}

This work was supported by the Key Project of Humanities and Social Sciences of Anhui Xinhua University under Grant no. 2018rw002 and supported in part by Anhui Provincial Quality Project in Colleges and Universities under Grant no. 2018 ylzy074.

\section{References}

[1] X. G. Yuan, P. Zou, J. Zhu, and D. Wu, "Development trend problems and countermeasures for cold chain logistics industry in China," Journal of Agricultural Science and Technology, vol. 17, no. 1, pp. 7-14, 2015.

[2] J. L. Yang and H. P. Hou, "Research on real-time monitoring optimization of cold-chain logistics big data," Science and Technology Management Research, vol. 6, pp. 198-203, 2017.

[3] J. H. Huang, F. Ye, and Q. Lin, "Government subsidy mechanism in agricultural supply chain considering capital constrain under random yield," Chinese Journal of Management, vol. 14, no. 2, pp. 277-285, 2017.

[4] F. Xiong, J. Peng, P. Jin, X. Y. Zhang, and Y. Qiu, “The impact of relational contracts stability about fresh agricultural product supply chain study: from the perspective of cold chain 
facilities subsidy mode," Chinese Journal of Management Science, vol. 23, no. 8, pp. 102-111, 2015.

[5] C. B. Li, E. J. Wang, and Y. Yang, "An evolutionary game study on cold chain logistics resource allocation under government supervision," Journal of Beijing Jiaotong University (Social Sciences Edition), vol. 16, no. 3, pp. 108-118, 2017.

[6] O. J. Mancur, The Logic of Collective Action: Public Goods and the Theory of Groups, Harvard University Press, Cambridge, MA, USA, 1965.

[7] Q. H. Zhu and Y. J. Dou, "A game model for green supply chain management based on government subsidies," Journal of Management Sciences in China, vol. 14, no. 16, pp. 86-95, 2011.

[8] A. Arya, B. Mittendorf, and D. E. M. Sappington, "The bright side of supplier encroachment," Marketing Science, vol. 26, no. 5, pp. 651-659, 2007.

[9] A. Dumrongsiri, M. Fan, A. Jain, and K. Moinzadeh, "A supply chain model with direct and retail channels," European Journal of Operational Research, vol. 187, no. 3, pp. 691-718, 2008.

[10] G. P. Cachon, "Supply chain coordination with contracts," in Handbooks in Operations Research and Management Science: Supply Chain Management, Chapter 6, S. Graves and T. de Kok, Eds., Elsevier, Amsterdam, Netherlands, 2003.

[11] J. Zhang, Q. Gou, L. Liang, and Z. Huang, "Supply chain coordination through cooperative advertising with reference price effect," Omega, vol. 41, no. 2, pp. 345-353, 2013.

[12] Y. D. Gong, B. Y. Li, and T. Liu, "Supply chain coordination strategy based on Shapley value and the same profit increase rate," Journal of Systems \& Management, vol. 18, no. 1, pp. 61-66, 2009.

[13] N. R. Xu and J. B. Liu, "Research on evaluation on agility of agile supply chain network based on complex network theory," Mathematical Problems in Engineering, vol. 2015, Article ID 707459, 10 pages, 2015.

[14] J.-B. Liu, J. Zhao, J. Min, and J. Cao, "The Hosoya index of graphs formed by a fractal graph," Fractals, vol. 27, no. 8, p. 1950135, 2019.

[15] J.-B. Liu, J. Zhao, and Z.-Q. Cai, "On the generalized adjacency, Laplacian and signless Laplacian spectra of the weighted edge corona networks," Physica A: Statistical Mechanics and Its Applications, vol. 540, Article ID 123073, 2020.

[16] J.-B. Liu, J. Zhao, H. He, and Z. Shao, "Valency-based topological descriptors and structural property of the generalized sierpiński networks," Journal of Statistical Physics, vol. 177, no. 6, pp. 1131-1147, 2019. 